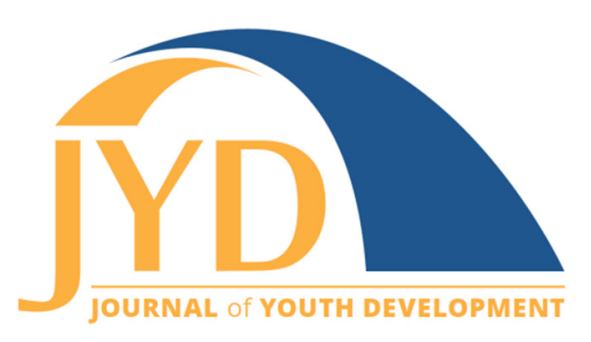

http://jyd.pitt.edu/ | Vol. 13 Issue 1-2 DOI 10.5195/jyd.2018.535 | ISSN 2325-4017 (online)

\title{
Does Theming Camp Experiences Lead to Greater Quality, Satisfaction, and Promotion?
}

\author{
Andrew Lacanienta \\ Texas A \& M University \\ a.lacanienta@tamu.edu
}

Gary Ellis

Texas A \& M University

gellis1@tamu.edu

Allen Taggart

University of Idaho

taggart@uidaho.edu

Jenny Wilder

Texas A \& M AgriLife Extension Service

jenny.wilder@ag.tamu.edu

Mark Carroll

Texas A \& M Agrilife Extension Service

jmcarroll@ag.tamu.edu

\begin{abstract}
Using themes (such as the Wild West or Survivor or Star Wars) in camp settings may enhance the quality of camp activities and youths' overall camp experience. We evaluated the effect of theming camp experiences on the quality of subjective experiences of campers. Campers $(\mathrm{N}=231$ ) in 3 sessions of a residential 4-H camp participated in the study. One camp session was fully themed (all activities used tangible and intangible props, cues, and imaginary story contexts), a second was partially themed (intangible cues and stories only), and the third was not themed. Questionnaires measuring the quality of immediate subjective experiences $(\mathrm{N}=1,847)$ were completed following each of 8 activity sessions (e.g., climbing, fishing, swimming). Campers also completed a questionnaire for the purpose of overall camp evaluation at the end of their camp sessions. Activity-level data were analyzed using linear mixed modeling techniques. Ordinary least-squares regression was used to analyze campers' overall camp experiences. Results at the activity level revealed significant theme-by-activity interaction effects. At the camp level, a hypothesized causal sequence linking theme to likelihood to recommend was supported.
\end{abstract}

Key words: narrative, summer camp, theme, theory of structured experience, quality

(cc) EY $_{\text {EY }}$ New articles in this journal are licensed under a Creative Commons Attribution 4.0 License. This journal is published by the University Library System, University of Pittsburgh and is cosponsored by the University of Pittsburgh Press. The Journal of Youth Development is the official peer-reviewed publication of the National Association of Extension 4-H Agents and the National AfterSchool Association. 


\section{Theming Camp Experiences}

Quality experiences of campers are imperative to the success of camps, particularly in the increasingly competitive camp industry (McCormack, 2016). Campers who enjoy deep, valued, and meaningful experiences will return as future opportunities allow and may also become active promoters who recommend the camp to their friends. Recommendations through social media and word-of-mouth advertising are keenly important, particularly during the era of mass electronic communication (e.g., Akrimi, \& Khemakhem, 2012; King, Racherla, \& Bush, 2014; Vinerean, Cetina, Dumiterescu, \& Tichindelean, 2013). Competition for campers can be intense. Camp managers are challenged to provide top-quality experiences that promote youth development and yield enthusiastic recommendations by campers to friends and family. Perhaps more importantly, deeply engaging experiences are the foundation for key developmental outcomes. Learning, talent development, creativity, and acquisition of new skills result from deep experiences that are high in challenge, concentration, interest, and enjoyment (Csikszentmihalyi, 1996; Reeve, 2013; Shernoff, Csikszentmihalyi, Schneider \& Shernoff, 2014; Shernoff \& Vandell, 2007).

Camps use a variety of strategies to promote these quality developmental experiences. They recruit talented and enthusiastic staff who strive to provide exciting arrays of camp activities and ensure that camper comfort, safety, and voice are in place (e.g., Ditter, 2016; Sheets \& Thoensen, 2014). Many camp experiences are structured using strategies that are shared with other facets of the experience industries, such as tourist attractions, restaurants, natural history interpretation, and heritage interpretation (e.g., Pine \& Gilmore, 2011; Tilden, 1959). Examples include theming events and activities, personalizing point-of-service encounters, expanding sensory appeals, and using provocation strategies during interpretation programs. Most camps actively use such techniques, but little is known about the efficacy of specific strategies or about possible mediating and moderating effects among them. This paper describes a field experiment conducted to evaluate one popular strategy, theming, on quality of experience by youth at a summer camp. Specifically, we addressed two research questions: (a) What effect does theme have on the quality of immediate subjective experiences of campers; and (b) Through what causal linkages might theme affect likelihood of campers to recommend the camp to others? 


\section{Theming Camp}

\section{Background}

\section{Theme}

A theme for a structured experience (such as a swim session at a camp) is defined as a set of verbal, physical, and interpersonal cues that invite participants to imagine they are in a different place, time, and/or set of circumstances (Ellis, Freeman, Jamal, \& Jiang, 2017). Theming is a key strategy for creating engaging, immersive, and absorbing experiences among organizations in the leisure industries (Duerden, Ward, \& Freeman 2015; Pine \& Gilmore 2011). Five principles are paramount in designing an appropriate and compelling theme. The theme must: (a) alter guests' sense of reality, (b) affect space, matter, and time, (c) facilitate a cohesive experience, (d) create multiple places in one, and (e) must fit the character of the experience stager (Pine \& Gilmore, 2011). Theme is crucial to quality experiences and "must drive all the design elements and staged events of the experience toward a unified storyline that wholly captivates the customer" (Pine \& Gilmore, 2011, p. 78).

Ellis and Rossman (2008) integrated theme and other concepts and principles from The Experience Economy (Pine \& Gilmore, 1999) with social science knowledge about customer service (e.g., Parasuraman, Zeithaml, \& Berry, 1988) into a model of strategies providers can use to structure experiences. Their model proposes that two sets of provider performance actions impact the quality of participants' subjective experiences: technical performance actions and artistic performance actions. Technical performance actions are basic service quality actions (e.g., providing clean bunks, reliable service, short waiting times at registration, functional equipment, friendly and courteous staff, and satisfactory food service). Technical performance actions are "dissatisfiers" (Herzberg, Mausner, \& Snyderman 1959; Kano, Seraku, Takahashi, \& Tsuji 1984); failure to perform technical actions at an acceptable level diminishes the quality of experience, but providing those actions at acceptable levels does not enhance participants' subjective experience quality.

Artistic performance refers to use of theme and other experience industry techniques identified by Pine and Gilmore (1999): unanticipated value added take-away, multisensory appeal, absence of negative cues, and customization to the level of the individual participant. Artistic factors are "satisfiers" and "delighters." Their effective use in structuring an activity is assumed to increase quality of participants' subjective experiences. Effective application of artistic performance actions yields positive subjective states, intentions to recommend, and positive memories. As an example of artistic performance, a jungle adventure theme might be introduced to a camp by providing campers with a small flashlight and a carabineer upon their 


\section{Theming Camp}

arrival (theme and unanticipated value added takeaway). These two items might be personalized with the child's name inscribed in the side (customize to the level of the individual). Throughout the camp experience, staff could intentionally program activity elements to engage the five senses by walking through "jungle mist" and searching for new smells in the jungle (multisensory appeal). Lastly, camp staff may strive to eliminate anything that takes away from the theme or indicates campers are not in a jungle adventure (eliminate negative cues). For example, garbage cans could be disguised to look like wooden barrels by wrapping them in brown paper.

Freeman Tilden (1959) emphasized the importance of theming interpretive experiences in Interpreting our Heritage, a pivotal and timeless source of information and inspiration among heritage and natural resource interpreters. Although Tilden did not refer to theme by that term, he emphasized that "interpretation should aim to present a whole rather than a part" (p. 9), and he devoted an entire chapter to that topic. The chapter, titled "The Story's the Thing," describes the importance of an evolving, coherent narrative in effective interpretation. "The interpreter who creates a whole," Tilden wrote, "and pares away all the obfuscating minor detail and drives straight toward the perfection of [the] story will find that...hearers are walking along...companions on the march" (p. 31).

Many camps immerse visitors in clear, coherent, and pervasive themes (e.g., wizards, cowboys, Disney stories, super heroes) in an effort to improve quality and facilitate developmental outcomes (Merhige, 2014), but empirical research on the effect of theme in camp settings is limited (e.g., Hayes \& MacLeod, 2007; Pikkemaat, Peters, Boksberger, \& Secco, 2009; Stricklin \& Ellis, in press; Wassler, Li, \& Hung, 2015). Despite the limited scientific evidence, examples of the power of theme in tourist attractions and built environments are evident. Disney, for example, receives nearly one third of its $\$ 45$ billion in revenue from its themed attractions (Sylt, 2014). Camps may possibly learn from the success of themed tourism attractions and use similar principles in theming camp settings.

\section{Themes and Developmental Outcomes: A Conceptual Framework}

A conceptual framework linking theme to elements of quality experience, developmental outcomes, and likelihood of recommending camp to others is presented in Figure 1. The first linkages in the framework propose that theme elevates two subjective experiences:

(a) engagement in the imaginary story implied by the theme, and (b) immersion in performing the actions required to participate. Two mechanisms produce this effect. Consistent with 
Figure 1. Author's Conceptual model of Theme Effect.

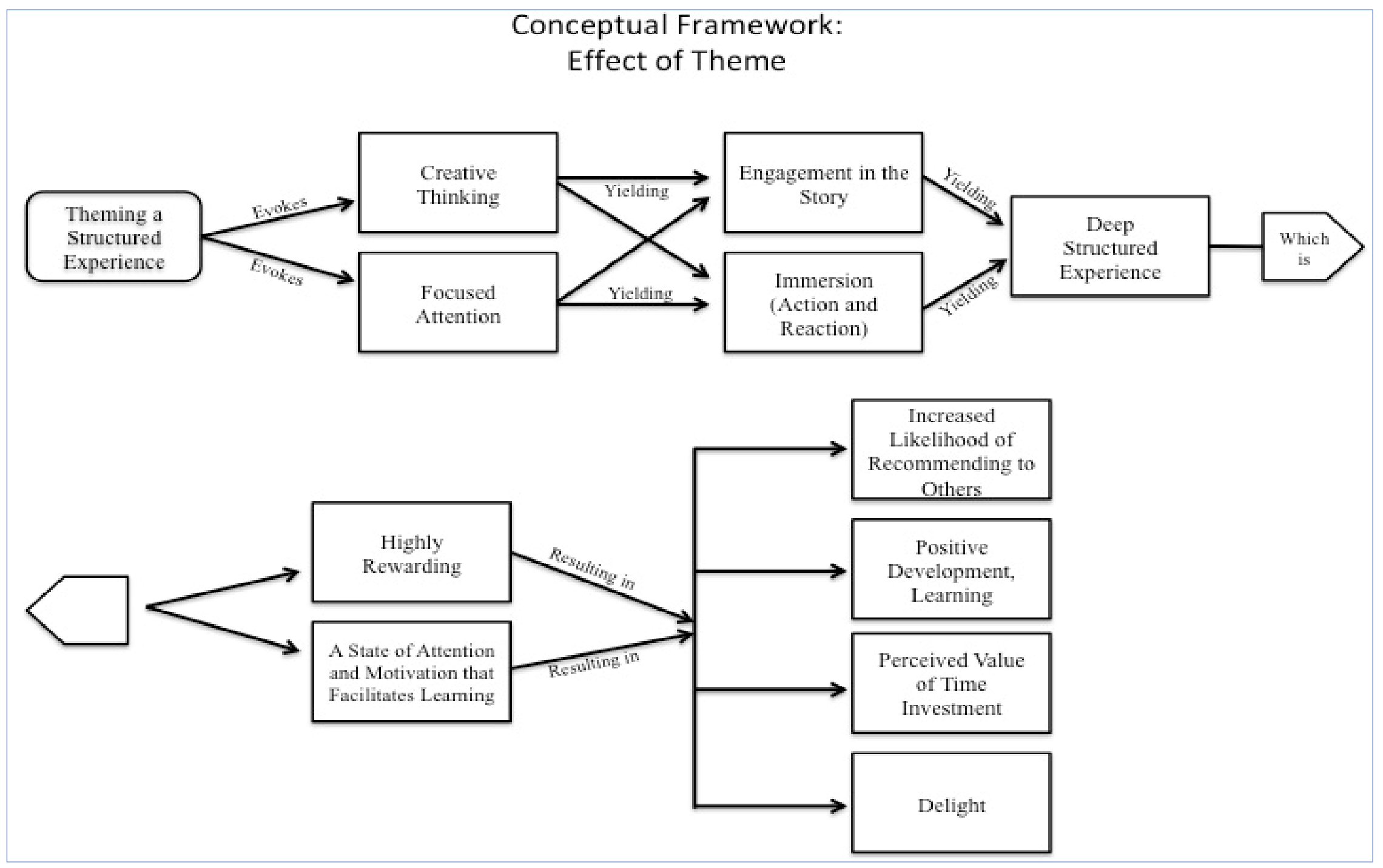




\section{Theming Camp}

Csikszentmihalyi (1996), Shernoff and Vandell (2007), and Shernoff et al. (2014) the cues and context of the theme evoke creative thought. The cues invite participants to imagine they are in a different place, time, or set of circumstances. Because themes are inherently novel and involve complex challenges (incongruity), arousal results and attention become more focused on the activity at hand. Creative production and learning are enhanced through this heightened level of attention and arousal (Berlyne, 1960; Bishop \& Jenreanaud, 1991; Hull, 1951). Theme thus elevates: (a) engagement in a story and (b) immersion in the action of participation in the activity.

These proposed effects are substitutable and stochastic (Zetterberg, 1963). In other words, strategies other than theme can elicit engagement and immersion, and engagement and immersion do not always follow the staging of a themed experience. As Prahalad and Ramaswamy (2004) stress, participants co-create experiences along with providers. Participants are always free to choose the way they direct their attention and actions with respect to an activity. Camp activity leaders know that some participants sometimes choose to disengage their attention fully from an activity while still being physically present. Therefore, it is important to provide opportunities for campers to participate in the creation, participation, and reflection of activities during camp.

The conceptual framework in Figure 1 also shows that increased engagement and immersion tend to produce a state of intense, deep experience. Deep experiences involve effortless focus of attention on a narrow stimulus field, a change in the perception of time passing, loss of consciousness of self, intense pleasure, and a feeling that actions are occurring automatically. These experiences have been described extensively in literature on subjective experience. Ackerman (1999) describes this state of experience as "deep play." Maslow (1962) described the nature and conditions of "ecstasy" and "peak experience." Csikszentmihalyi's (1975) "flow" concept has extensive presence in literature in psychology, leisure studies, management, education, and the arts. The theory of structured experience (Ellis, Freeman, et al. 2017) focuses on deep experience within discrete "structured experiences" (i.e., experiences staged by a provider), and uses the term, "deep structured experience."

The latter portions of the framework show that deep structured experience is extremely pleasurable, and the heightened state of activation that is part of deep structured experience facilitates learning (Berlyne, 1960; Bishop \& Jenreanaud, 1991; Hull, 1951). Thus, as Csikszentmihalyi (1988) has stressed, positive development and learning are facilitated by deep structured experience. In addition, the rewarding nature of the pleasurable experience 


\section{Theming Camp}

increases the likelihood of the participant recommending the experience to others through social exchange. Pleasurable experiences are valued and delightful.

\section{Quality Experiences}

The concept of quality has been defined in many ways in the youth development literature. Baldwin, Stromwall, and Wilder (2015) provided evidence of over 3,000 indicators of quality. A common definition of quality is thus elusive and debatable. Despite the ambiguity that results from these diverse indicators, youth program quality is "widely regarded as the best predictor of risk prevention and positive developmental outcomes" (Silliman \& Schumm, 2013, p. 649). One approach has been to define quality in terms of availability to youth development programs. From that perspective, "quality is best defined as access to key developmental experiences [occurring] at the point of service: the place where youth and program intersect" (Smith, Akiva, Arrieux, \& Jones 2006, p. 94; Smith, Peck, Denault, Blazevski, \& Akiva, 2010). Another approach to quality is focusing on "coexistence and correspondence between staff practices and youth experience that is likely to produce positive developmental change" (Smith et al., 2010, p. 359). Indeed, focus on staff behavior and practice has been shown to elevate the quality of youth experience (Smith, Devaney, Akiva, \& Sugar, 2009).

Staged, deep structured experiences yield a variety of outcomes indicative of quality. For the purpose of this paper quality is defined by the consumer (i.e., camper; Peters, 1987) and can be operationalized by examining levels of delight, perceived value, deep structured experience, and likelihood to recommend (Ellis, Freeman, et al., 2017). Our definition of quality falls in line with literature on point-of-service quality. Specifically, how, "point of service quality speaks to the nuts and bolts of youth experiences and includes discrete staff practices that directly influence youth outcomes and can be the subject of program improvement efforts" (Yohalem, Granger, \& Pittman, 2009, p. 131).

\section{Likelihood to Recommend}

Likelihood of recommending can be defined as the probability of recommending a product or service to others. The net-promoter score (NPS) is a measure of this likelihood and is considered to be among the key indicators of an organization's success (Reichheld, 2003). NPS is widely used in practice and research (Schneider, Berent, Thomas, \& Krosnick, 2008). Customers respond to a single item, showing their intent to recommend the economic offering to others. Scores are correlated with quality, loyalty, growth, and actual promotion behavior 
Journal of Youth Development | http://jyd.pitt.edu/ | Vol. 13 Issue 1-2 DOI 10.5195/jyd.2018.535

\section{Theming Camp}

(Reichheld, 2003). Although NPS has not been used in youth development research, it has been used in public and nonprofit organizations (Ni, 2014).

\section{Hypotheses}

Based on the Author's conceptual model described in this section the following hypotheses were tested:

- $\mathrm{H}_{1}$ : Themed activities yield higher quality of immediate structured experiences than nonthemed activities.

- $\mathrm{H}_{2}$ : High-quality immediate structured experiences (i.e., camp activities) yield high overall evaluations of camp experiences.

- $\mathrm{H}_{3}$ : High overall evaluations of camp experiences yield a higher likelihood that campers will recommend the camp to others.

\section{Method}

\section{Setting and Sample}

This study was conducted at a residential 4-H nature-based summer camp. Camps were three days in duration. Each camp session included eight core activities: archery, riflery, kayaking, fishing, crafts, challenge course, swimming, and dance. The sample included 1,847 experience observations from 231 campers. Participants' ages ranged from 8 to 17 years old and $61.5 \%$ were female.

\section{Measurement}

A paper and pencil questionnaire was provided to each camper upon his or her arrival at camp. The questionnaire was in the form of a booklet and included name, group, age, gender, and number of years campers had previously attended an outdoor summer camp. Researchers trained activity staff and camp counselors on how to use the questionnaires and also oriented campers to the questions. Camp staff held the questionnaire booklets and distributed them to campers immediately following each activity. If campers did not understand a question or needed help, camp staff were readily available to assist them. 


\section{Experience-Level Measures}

The first set of instruments was administered to campers following each of the eight core activities. Variables measured included prevalence of deep structured experience (DSEe), delight (De), and perceived value of time investment (PVe).

\section{Deep structured experience prevalence}

DSEe was a six-item scale. The response format for each item was a line in which participants would indicate how they felt during the activity ranging from "none of the time" to "all of the time" An example of one of the items in the scale is "I was totally focused on this activity." Scores were calculated by measuring in millimeters from the beginning of the line until the mark made by participants and calculated into a percentage. The alpha reliability estimate was good (.82).

\section{Delight}

Delight yielded by the immediate experience (De) was based on the perspective that delight is an extreme form of satisfaction, ranging from "disgust" at one end of a continuum to "delight" on the other (Schneider \& Bowen, 1999; Torres \& Kline, 2006; 2013). The single-item scale asked participants to "circle the face that best shows how much you liked or disliked the activity" with a spectrum of five smiley faces ranging from delighted to disgusted.

\section{Perceived Value of Time Investment}

Perceived value of time investment of the immediate experience (PVe) was a three-item scale. The response format was a five-item Likert-scale. Participants were instructed to "mark the circle showing how you feel about this activity" on a five-point scale. An example item was "this activity was an excellent use of my time." The alpha reliability estimate was good $(.80)$.

\section{Camper Level Measures}

The second set of instruments measured the quality of campers' overall camp experience. These measures were taken on the last day of camp. Overall camp experience measures included perceived value (PVo), delight (Do), engagement (Eo), and net promoter scale (NPS; Schneider et al., 2008). 


\section{Overall Camp Delight}

(Do) was a single-item measure identical to the delight scale used to measure individual immediate experiences (De). The point of reference, though, was campers' overall experience at camp rather than an individual activity.

\section{Overall Camp Perceived Value}

Perceived value of overall time investment (PVo) was a four-item scale that used the same response format as PVe, but the context was the overall camp experience. A previous study found acceptable alpha reliability $(\alpha=.82$ ) in a youth population (Ellis, Taggart, Martz, Lepley, $\&$ Jamal, 2017). The alpha reliability estimate for the scale during this study was acceptable at .83 .

\section{Overall Camp Engagement}

Engagement overall (Eo) was a four-item scale. The response format for this measure asked participants to mark on a line from "none of the time" to "all of the time" on how they felt during the entire time at camp. One item stated, "I felt excited about things we were doing." Scores were calculated by measuring in millimeters from the beginning of the line until the mark made by participants and calculated into a percentage. A previous study found acceptable alpha reliability of .71 (Ellis, Taggart, et al., 2017). The alpha reliability estimate for the scale during this study was acceptable at .67.

\section{Overall Camp Recommendation Likelihood}

The likelihood among campers to recommend the camp was measured using the "Net Promoter" score method (NPS; Reichheld, 2003). A single-item measure asked, "On a scale of 0-10, how likely are you to recommend Camp Brownwood to a friend?" The resulting measure provided an indication of likelihood of recommending (Reichheld, 2003).

\section{Procedure}

Camp I was not themed, Camp II was partially themed, and Camp III was fully themed. During the non-themed camp session, staff members told no narrative story and used no props during camp activities. During the partially themed camp session, a story narrative was in place for each camp activity without the use of props, decorations, or memorabilia. During the fully 


\section{Theming Camp}

themed camp session, the camp staff integrated a story throughout each of the eight activities and assisted with props, decorations, and memorabilia.

Before the camp season began, camp staff members were asked to create a theme for the summer and a "Texas/Western" theme was chosen. Researchers then trained staff how to use narrative storyboarding (Merhige, 2014) to design and implement the theme during the activity sessions (see Appendix). Activity specialists also created narratives for each activity and secured associated props as appropriate. During the climbing experience, for example, campers in the themed treatment condition "became" gold miners. They had successfully mined a large pot of gold, but bandits were in hot pursuit. They had to climb a bluff (cargo net) and slide down the side of the bluff (zip-line) to escape.

\section{Analysis}

First, we hypothesized that the presence of a theme enhances the quality of experience during each of the eight activities. Some activities may lend themselves to theme better than others. Thus, in addition to the main effects, we included the interaction between theme and activity in the linear mixed models predicting DSEe, PVe, and De. "Camper" was a random-effects variable in these linear mixed models, accounting for the lack of independence of observations created by the repeated measures design.

Next, we aggregated the experience-level data to produce average delight and perceived value scores across all eight activities for each camper ( $P V_{\text {mean }}$ and $\left.\mathrm{D}_{\text {mean }}\right)$. The resulting vectors of means were added to a causal model leading to likelihood to recommend the camp (Figure 2). We noted that campers whose average quality of individual immediate experience (i.e., $\mathrm{PV}$ mean and $D_{\text {mean }}$ ) was high should also report higher values on the corresponding overall camp measures (PVo and Do). Finally, to complete the causal model, we regressed NPS on the three overall evaluations of camp (i.e., PVo, Do, and Eo). Ordinary least squares regression was used to test the coefficients in the causal model. Coefficients in Figure 2 are standardized regression coefficients (beta weights). 
Theming Camp

Figure 2. Path Model

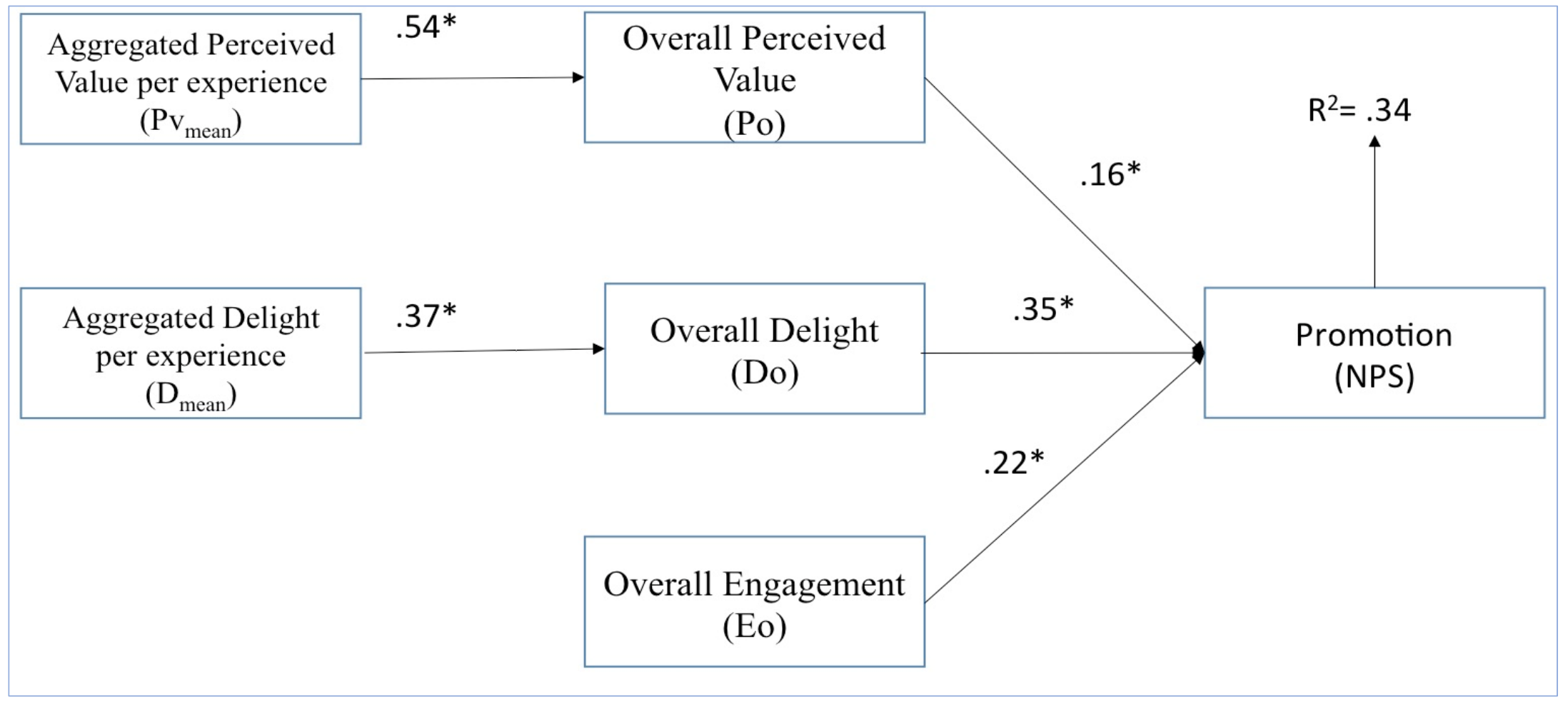

Path analysis results are summarized in Figure 2. All hypotheses were supported. Coefficients ranged in magnitude from .16 (NPS and $\mathrm{PVo}$ ) to .54 ( $\mathrm{PV}_{\text {mean }}$ and $\mathrm{PVo}$ ). The $\mathrm{R}^{2}$ in predicting likelihood to recommend was .34 . 


\section{Results}

\section{Descriptive Statistics}

Descriptive statistics are shown in Table 1. Extreme negative skewness and positive kurtosis were evident in distributions of all but two of the variables (deep structured experience prevalence and engagement). These results indicate the need to revise measures in a way that yields greater variance at high levels in future research.

Table 1. Descriptive Statistics for Experience and Camp-Level Variables

\begin{tabular}{|c|c|c|c|c|c|c|c|c|c|c|}
\hline Experience-Level Variables & $\boldsymbol{N}$ & $M$ & $S D$ & SK & $\boldsymbol{K}$ & \# of items & DSEe & De & Pve & \\
\hline DSE (DSEe) & 1,783 & 65.4 & 22.31 & -0.68 & -0.06 & 5 & 0.82 & - & - & \\
\hline Delight (De) & 1,794 & 4.34 & 0.92 & -1.45 & 1.79 & 1 & $0.58^{*}$ & - & - & \\
\hline Perceived value (Pve) & 1,717 & 4.3 & 0.97 & -1.5 & 1.73 & 3 & $0.54 *$ & $0.69 *$ & 0.80 & \\
\hline Overall Camp-Level Variables & $\boldsymbol{N}$ & $M$ & $S D$ & SK & $\boldsymbol{K}$ & \# of items & NPS & Pvo & Do & Eo \\
\hline Net promoter score (NPS) & 212 & 8.99 & 1.77 & -2.43 & 6.65 & 1 & - & - & - & - \\
\hline Perceived value (PVo) & 209 & 4.68 & 0.63 & -2.62 & 8.41 & 4 & $.46^{*}$ & 0.83 & - & - \\
\hline Delight (Do) & 214 & 4.72 & 0.56 & -2.58 & 9.66 & 1 & $.52 *$ & $.66 *$ & - & - \\
\hline Engagement (Eo) & 213 & 0.74 & 0.2 & -0.75 & 0.05 & 4 & $.37 *$ & $.29 *$ & $.31 *$ & 0.67 \\
\hline
\end{tabular}

Note: Coefficients on principle diagonal are alpha coeffients $* \mathrm{p}<.01 ; \mathrm{M}=$ mean; SD = standard deviation; SK = skewness; $\mathrm{K}=$ kurtosis 


\section{Hypothesis Tests}

The mixed-models analysis of the activity-level data showed a significant, theme-by-activity interaction effect on all three measures of immediate experience (Table 2). In the presence of significant interactions, main effects must be interpreted with caution (e.g., Maxwell \& DeLaney, 1984). The interaction effects were plotted to facilitate interpretation (Figure 3). Themed activities provided greater deep structured experience prevalence for all activity types (Figure $3 a)$, but the magnitude of the effect differed by activity. The largest effect was swimming and the smallest was riflery. Perceived value and delight were higher following non-themed dance and fishing activities.

Table 2. Theme-by-Activity Interaction Effects on DSEe, PVe, and De

\begin{tabular}{|l|l|l|}
\hline & $\boldsymbol{F}$ & $\boldsymbol{d f}$ \\
\hline Deep structured experience (DSEe) & & \\
\hline Theme & 1.75 & 226.46 \\
\hline Activity & $8.53^{*}$ & 1543.57 \\
\hline Theme $x$ activity & $2.22^{*}$ & 1543.61 \\
\hline & & \\
\hline Perceived value of Time Investment (PVe) & & \\
\hline Theme & 0.81 & 219.05 \\
\hline Activity & $15.11^{*}$ & 1477.68 \\
\hline Theme $x$ activity & $3.08^{*}$ & 1477.87 \\
\hline & & \\
\hline Delight (De) & & \\
\hline Theme & 0.2 & 224.22 \\
\hline Activity & $10.87^{*}$ & 1545.11 \\
\hline Theme $\times$ activity & $2.11^{*}$ & 1545.37 \\
\hline \hline .01 & & \\
\hline
\end{tabular}

$* p<.01$ 
Journal of Youth Development | http://jyd.pitt.edu/ | Vol. 13 Issue 1-2 DOI 10.5195/jyd.2018.535

Theming Camp

Figure 3. Interaction Effect of Theme by Activity on (a) Deep Structured Experience, (b) Perceived Value, and (c) Delight

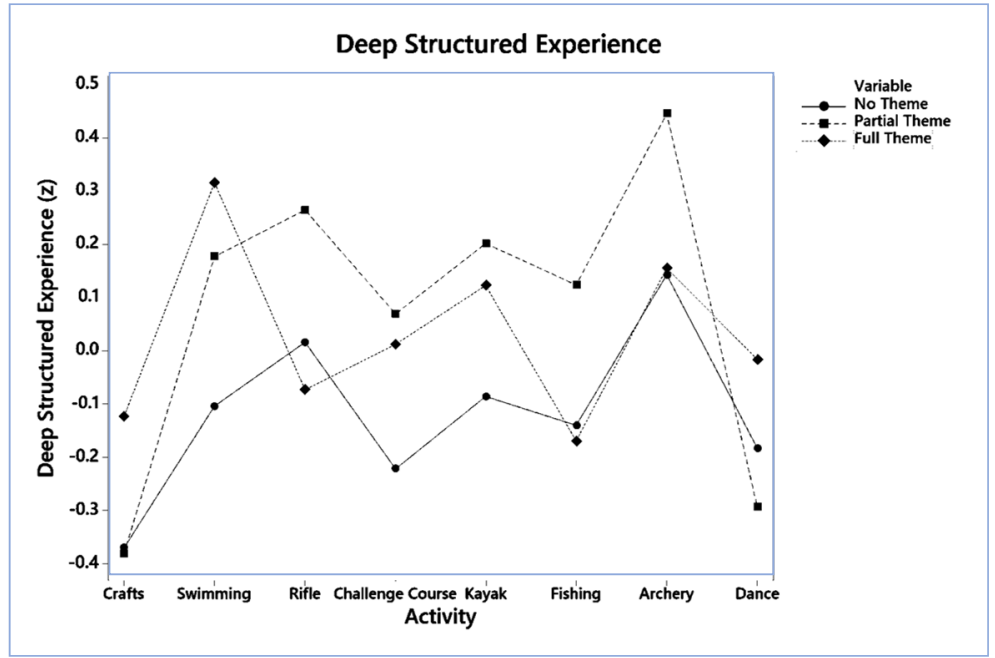

Figure 3a. Deep Structured

Experience

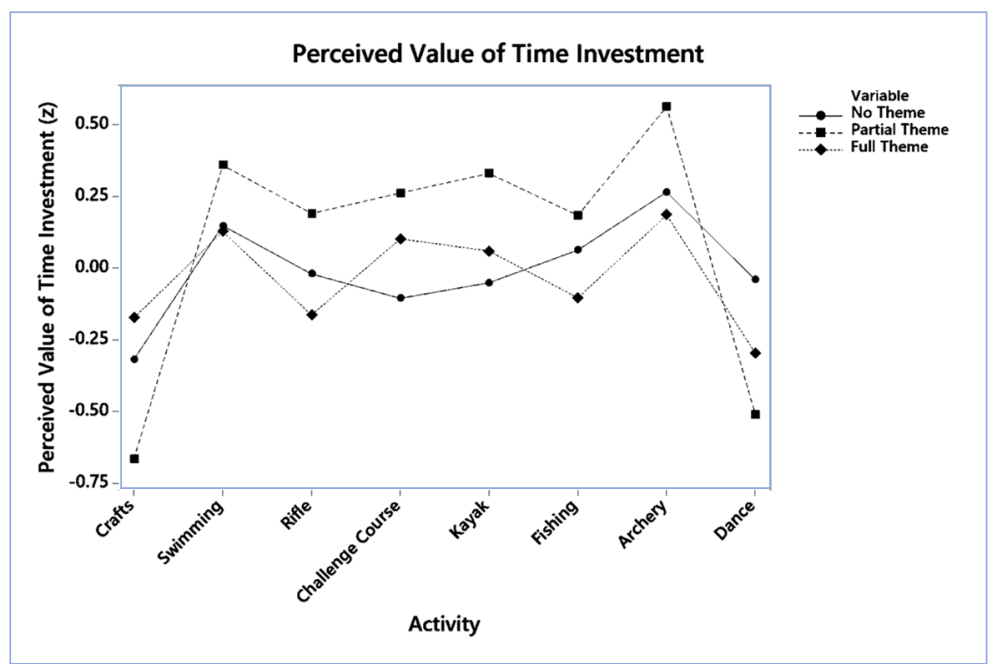

Figure 3b. Perceived Value

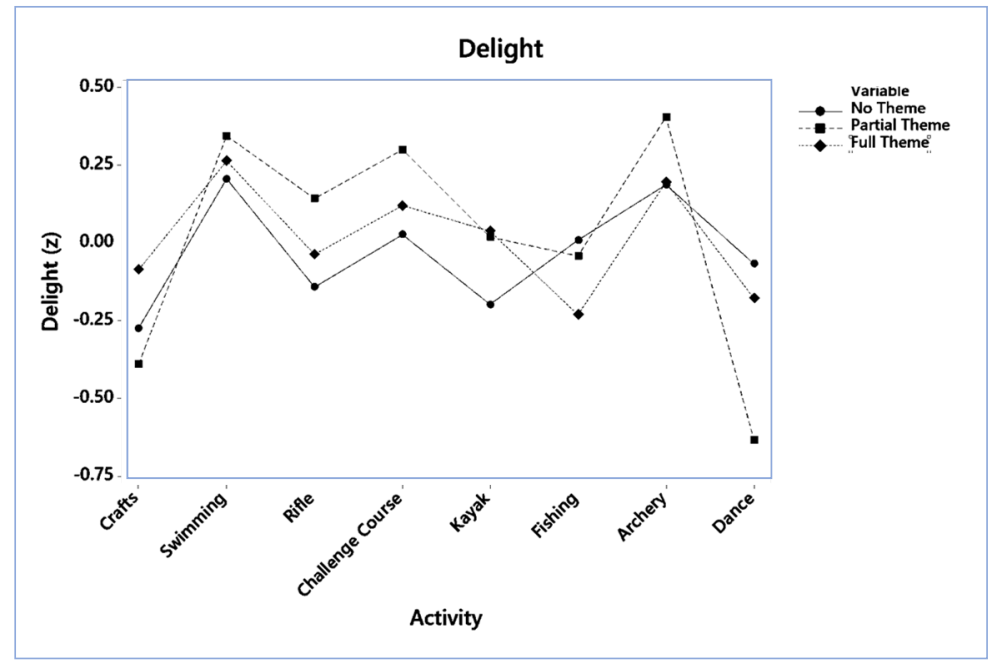

Figure 3c. Delight 
Theming Camp

\section{Discussion}

This study addressed two questions: (a) What effect does theme have on the subjective quality of immediate experiences of youth campers; and (b) Through what causal linkages might theme affect the likelihood to recommend the camp to others? Findings provide new insight into both of these questions. Theme was found to influence experience quality, but the significant interaction effect indicates that theme may be more important in some activities than others. Path analysis results support the causal linkages suggested by the theory of structured experience (Ellis, Freeman, et al., 2017). Very generally, theme by activity affects the quality of immediate experiences and, as the quality of individual immediate experiences increases, the perception of quality of the overall camp experience also increases. Ultimately, delight and perceived value of time investment result in campers having greater likelihood to recommend the camp to family and friends.

A reader might ask if we would recommend theming, based on the findings of this study. If the goal is to increase the quality of experience, we would reply that we would indeed recommend theming. Our response is founded in the significant interaction effect, the pattern of means in the data (Figure 3), and in our own subjective observations on-site. In brief, using theme increases the probability of greater prevalence of deep structured experiences (Figure 3a), of higher perceived value of time investment (Figure 3b), and greater delight (Figure 3c), though the strength of the effect may vary across different activities. The interaction effect and the pattern of means support this recommendation. In Figure 3, the three group means are plotted for each of eight activities and for each of the three dependent variables (deep structured experience, perceived value, and delight). Thus, a total of 24 opportunities exist for any given group to have the highest mean for a given activity. If theme had no effect, we would expect each of the three camp types to have the highest mean following approximately one-third of the activities (8 out of 24). The same would be true for how often we would expect a given camp type to have the lowest mean (i.e., the probability would be around .33). But consistent with the significant interaction effect, the patterns of means depart significantly $\left(X^{2}=6.24\right.$, $p<.05)$ from these "expected values." The no-theme group had the lowest mean on 13 of the 24 occasions (54\%), and that group had the highest mean on only three occasions (12.5\%). Two of the three occasions on which the no-theme group mean was highest involved the dance activity. Means of perceived value and delight were highest for the no-theme group following the dance activity. Subsequent researchers would do well to investigate the use of theme for dance activities; contrary to the long tradition of theming dances, perhaps theme does not further elevate experiences beyond the natural appeal of the dance activity. Another reasonable 


\section{Theming Camp}

explanation is that the story we embedded in the theme for this study was not effective for the dance activity.

This latter observation gives rise to discussion of a key limitation of this study. We defined theme as a set of verbal, physical, and nonverbal cues that invite participants to imagine they are in a different place, time, or set of circumstances. That definition was the basis for designing and implementing themes for each of the eight activities. It is very important, though, to note that a key element of theme, the "story" itself, was not constant across activities. The story within the theme for fishing, for example, was very different than the story within the theme for archery. Although cues were used to suggest stories during all activities and all fit within the western theme, the stories and cues themselves were very different across the eight activities. Methodologically, this unmeasured and uncontrolled "story" effect was confounded with the "activity" effect. Given this confounding, we have no way of knowing if a high mean for a particular group and activity is a result of the story, the cues, or other features of the activity (e.g., the time of day). Future research is needed to understand the effect of the story itself on the quality of subjective experiences of campers participating in themed activities.

Another reason that we would recommend theming is our subjective observations during the camp sessions. Our impressions were that themed sessions enhanced enthusiasm. Campers enjoyed both the full and partial themes, and they sometimes talked about the stories within the themes even after the activities were completed. Perhaps more importantly, we noted that camp staff became excited about creating themes and devising strategies for implementing the themes. Camp managers emphasize the importance of activity specialists remaining enthusiastic and engaged throughout the camp season. Additionally, it is these staff interactions that may place a role in facilitating positive youth development outcomes (Yohalem, et al., 2009). We recommend future research be conducted on how theme affects motivation of camp staff. A fine contribution would either be a rigorous qualitative phenomenology or a quantitative study using a design controlling the inherent bias in unstructured observation.

Results provide insight into how structured experiences may contribute to the success of a given camp within the competitive camp industry. Experience techniques such as theming seem to elevate the quality of experiences, initiating a sequence of causes and effects that result in greater propensity of campers to recommend the camp to friends and family. The study is thus a contribution to the growing body of knowledge about the experience industries. Results are consistent with Pine and Gilmore's (2011) observations about the effect of theme. Results are also consistent with Merhige's (2014) recommendation to use themes such as the Wild West, 


\section{Theming Camp}

Survivor, or Star Wars in youth camp settings as they may enhance the quality of camp activities and youths' overall camp experience. Results also support select propositions about theme within the theory of structured experience (Ellis, Freeman, et al., 2017).

Returning to our question regarding recommending theme to camp professionals, we would point out that the cost to theme a camp can be very modest. Only a few dollars are required, along with a handful of hours in training. With modest investment, staff can identify an exciting theme, create an experience plan for each activity, and purchase the necessary props. Many camps struggle with funding constraints. Themes may be a way for some camp directors and program coordinators to enhance the quality of the camp experiences while pools of funds are being assembled for major new attractions.

\section{Additional Limitations and Future Research}

One notable limitation and area for future research was the number of camp sessions per condition. There was only one camp per condition (i.e., no theme, partial theme, full theme). Each set of camps at this particular summer camp include a variety of specific age groups. This study was intentionally designed to include the three camps that contained the same age groups in an effort to keep the age range similar for each of the three treatment conditions.

The extreme negative skewness and positive kurtosis in the data are notable. That is, the responses for these questionnaires were all quite high (e.g., on a 5-point scale many responses were three, four, or five). These distributions indicate the need for improved measurement. A "ceiling effect" (i.e., a lack of variance) is evident; the response scales were not sufficient to generate potentially discriminating variance. Future data collection in youth camp settings might benefit from measures that afford greater opportunity for variability. Our measure of deep structured experience provides an example of an approach that may prove effective. One of the items stated, "Time flew by." Responses were provided along a single line, with "none of the time" at one end and "all of the time" at the other end. Participants placed an X on the line to indicate to how much of the time during the experience time did, in fact, "fly by." Researchers measured from the beginning of the line to the $X$ in millimeters. Scores were the percentage of the line up to the "X." This measure had acceptable reliability for research purposes $(a=.67)$. Skewness $(\mathrm{sk}=-0.75)$ and kurtosis $(\mathrm{k}=.05)$ measures showed that the distribution approximated a normal curve. In contrast, distributions of overall delight and overall perceived value of time investment showed extreme negative skewness and high kurtosis (i.e., all of the responses were grouped together near the high end of the scale). Overall perceived value of 


\section{Theming Camp}

time investment and overall delight had only five possible response options. Because camp is generally highly satisfying and response choices were few these scales may have lent themselves to extreme values of skewness and kurtosis.

Future research is needed to replicate this study in different settings among different populations and age groups. Our sample largely consisted of younger adolescents and while we hypothesize theme has a similar engaging effect on all ages future research might explore how theme is related to quality experiences among a variety of age groups. Theme may show positive relationships with experience quality in situations such as dance socials, parties, restaurants, or clubs where theme may lend itself well to the situation. On the other hand, negative relationships between theme and experience quality might exist in situations like a university classroom, a courtroom, or other instances where theme may cause more distraction than benefit. Future research on the operationalization and measurement of theme is also needed. We operationalized theme as a narrative with associated props, but there is a variety of extraneous variables such as setting, music, lighting, food, voice, dialogue, and acting that may play a salient role in theming.

While this study focused on one aspect of experience design-theming-there are additional experience design related principles that may be applied in youth camp settings. Future research might explore how memorabilia, multi-sensory experiences, gamification, and cocreation relate to experience quality, satisfaction, and memorability of camp experiences.

\section{Practitioner Recommendations}

- Do consider theming your camp experiences. You can expect themes to elevate the quality of experience in camp activities and the enthusiasm of your staff.

- An effective theme begins with your camp staff. Allow the camp staff to have a say in the overall camp theme and fully empower them to create, design, and implement themes within activity sessions they lead. Choose one staff member to be in charge of theme implementation and quality control.

- After choosing an overarching theme a narrative storyboard can help to create a narrative for each portion of the camp (i.e., activities, dances, meals, etc.). One portion of camp staff training may include creating a narrative storyboard for the activity, testing it with other camp staff, and making adjustments according to staff feedback. Please see Appendix for a narrative storyboard template. 
Journal of Youth Development | http://jyd.pitt.edu/ | Vol. 13 Issue 1-2 DOI 10.5195/jyd.2018.535

\section{Theming Camp}

- Let campers know what the theme is ahead of time so they can prepare accordingly. If your theme is super heroes, for example, campers' anticipation before camp may increase as they prepare super hero outfits for select camp activities.

Themes at camp are an efficient use of resources and are an effective way to engage staff and campers. It is key to remember though, that not just any story will do. High quality narratives, intentional use of costumes, dialogue, and props, and well-executed activities are only the beginning. Even after initiating a theme it is crucial the theme is cohesive, pervasive, and otherwise effectively implemented.

\section{References}

Ackerman, D. (1999). Deep play. New York, NY: Vintage Books.

Akrimi, Y. \& Khemakhem, R. (2012). What drives consumers to spread the word in social media? Journal of Marketing Research and Case Studies, 2012, 1-14.

Baldwin, C. L., Stromwall, K., \& Wilder, Q. (2015). Afterschool youth program design and structural quality: Implications for quality improvement. Child \& Youth Services, 226-247.

Berlyne, D. E. (1960). Conflict, arousal, and curiosity. New York, NY: McGraw-Hill. Retrieved from http://psycnet.apa.org/doi/10.1037/11164-000

Bishop, D. \& Jeanrenaud. C. (1991). Creative growth through play and its implications for recreation practice. In T. Goodale \& P.Witt (Eds.), Recreation and leisure: Issues in an era of change, (pp. 183-199). State College, PA: Venture.

Csikszentmihalyi, M. (1975). Beyond boredom and anxiety. San Francisco, CA: Jossey-Bass.

Csikszentmihalyi, M. (1988). The flow experience and its significance for human psychology. In M. Csikszentmihalyi \& I. S. Csikszentmihalyi (Eds.), Optimal experience: Psychological studies of flow in consciousness (pp. 15-35). New York, NY: Cambridge University Press.

Csikszentmihalyi, M. (1996). Creativity: Flow and the psychology of discovery and invention. New York, NY: Harper Collins.

Ditter, B. (2016). Camp leadership for the $21^{\text {st }}$ century. Camping Magazine. January/February, 32-35.

Duerden, M. D., Ward, P. J., \& Freeman, P. A. (2015). Conceptualizing structured experiences: Seeking interdisciplinary integration. Journal of Leisure Research, 475), 601-620.

Ellis, G. D., Freeman, P. A., Jamal, T., \& Jiang, J. (2017). A theory of structured experience. Annals of Leisure Research, 1-22.

Ellis, G. D., \& Rossman, J. R. (2008). Creating value for participants through experience staging: Parks, recreation, and tourism in the experience industry. Journal of Park \& Recreation Administration, 26(4). 
Journal of Youth Development | http://jyd.pitt.edu/ | Vol. 13 Issue 1-2 DOI 10.5195/jyd.2018.535

\section{Theming Camp}

Ellis, G. D., Taggart, A. S., Martz, J., Lepley, T., \& Jamal, T. (2017). Monitoring structured experiences during youth programs: Development of brief measures of perceived value and engagement. Journal of Youth Development, 11(3), 159-174.

Hayes, D., \& MacLeod, N. (2007). Packaging places: Designing heritage trails using an experience economy perspective to maximize visitor engagement. Journal of Vacation Marketing, 13(1), 4558.

Herzberg F., Mausner, B. \& Snyderman, B. (1959). The motivation to work. New York, NY: Wiley. Hull, C. L. 1951. Essentials of behavior. New Haven, CT: Yale University Press.

Kano, N., Seraku, N., Takahashi, F., \& Tsuji, S. (1984). Attractive quality and must-be quality, hinshitsu. The Journal of the Japanese Society for Quality Control, 39-48.

King, R. A., Racherla, P., \& Bush, V. D. (2014). What we know and don't know about online word-ofmouth: A review and synthesis of the literature. Journal of Interactive Marketing, 28(3), 167-183.

Maslow, A. (1962). Lessons from the peak-experiences. Journal of Humanistic Psychology 2 (1): 9-18.

Maxwell, S. E. \& Delaney, H. D. (1984). Designing experiments and analyzing data. Mahwah, N.J.: Lawrence Erlbaum Associates.

McCormack, R. (2016). IBISWorld industry report OD5349. Summer Camps in the US. Retrieved August 30, 2017 from: http://clients1.ibisworld.com/reports/us/industry/default.aspx?entid=5349.

Merhige, J. (2014). Programming with a theme. Camping Magazine. Retrieved from https://www.acacamps.org/resource-library/camping-magazine/programming-theme

$\mathrm{Ni}, \mathrm{P}$. (2014) The net promoter score for nonprofit and public programs: Beneficiary feedback. Retrieved from: http://feedbacklabs.org/blog/the-net-promoter-score-for-nonprofit-and-public-programsbeneficiary-feedback/

Parasuraman, A., Zeithaml, V. A., \& Berry, L. L. (1988). Servqual: A multiple-item scale for measuring consumer perceptions of service quality. Journal of Retailing, 64(1), 12.

Peters, T. 1987. Thriving on chaos: Handbook for a management revolution. New York, NY: Harper and Row.

Pikkemaat, B., Peters, M., Boksberger, P., \& Secco, M. (2009). The staging of experiences in wine tourism. Journal of Hospitality Marketing \& Management, 18(2-3), 237-253.

Pine, B. J., \& Gilmore, J. H. (1999). The experience economy: Work is theatre \& every business a stage. Boston: Harvard Business Press.

Pine, B. J., \& Gilmore, J. H. (2011). The experience economy. Boston, MA: Harvard Business Press. Prahalad, C. K., \& Ramaswamy, V. (2004). The future of competition. Boston, MA: Harvard Business Press.

Reeve, J. 2013. A self-determination theory perspective on student engagement. In S. Christenson, A Reschly, and C. Wylie (Eds.), Handbook of research on student engagement, (pp. 149-172). Boston, MA: Springer. 
Journal of Youth Development | http://jyd.pitt.edu/ | Vol. 13 Issue 1-2 DOI 10.5195/jyd.2018.535

\section{Theming Camp}

Reichheld, F. (2003). The one number you need. In: Harvard Business Review, 81(12), 46-54.

Schneider, B., \& Bowen, D. E. (1999). Understanding customer delight and outrage. Sloan Management Review, 41(1), 35-45.

Schneider, D., Berent, M., Thomas, R., \& Krosnick, J. (2008, May). Measuring customer satisfaction and loyalty: Improving the 'Net-Promoter' score. Poster presented at the Annual Meeting of the American Association for Public Opinion Research, New Orleans, Louisiana.

Sheets, A. \& Thoensen, D. (2014). The business of camp. Monterry, CA: American Camp Association.

Shernoff, D. J., Csikszentmihalyi, M., Schneider, B., \& Shernoff, E. S. (2014). Student engagement in high school classrooms from the perspective of flow theory. In Applications of Flow in Human Development and Education (pp. 475-494). Netherlands: Springer, Dordrecht. doi: 10.1007/97894-017-9094-9_24

Shernoff, D. \& Vandell, D. 2007. Engagement in after-school program activities: Quality of experience from the perspective of participants. Journal of Youth Adolescence. (36), 891-903. doi: 10.1007/s10964-007-9183-5.

Silliman, B., \& Schumm, W. R. (2013). Youth program quality survey: Youth assessment of program quality. Marriage \& Family Review, 647-670.

Smith, C., Akiva, T., Arrieux, D., \& Jones, M. M. (2006). Improving quality at the point of service. New Directions For Youth Development, 93-108.

Smith, C., Devaney, T. J., Akiva, T., \& Sugar, S. A. (2009). Quality and accountability in the out-ofschool-time sector. New Directions For Youth Development, 109-127.

Smith, C., Peck, S. C., Denault, A.-S., Blazevski, J., \& Akiva, T. (2010). Quality at the point of service: Profiles of practice in after-school settings. American Journal of Community Psychology, 358-369.

Stricklin, M. \& Ellis, G. (in press). Effects of experience structuring strategies on perceived value and subjective experience of event participants. Event Management.

Sylt, C. (2014). The secrets behind Disney's $\$ 2.2$ billion theme park profits. Forbes Magazine. Retrieved from: https://www.forbes.com/sites/csylt/2014/07/14/the-secrets-behind-disneys-2-2-billiontheme-park-profits/\#3e23d5d584fb

Tilden, F. (1959). Interpreting our heritage. Chapel Hill: University of North Carolina Press.

Torres, E., \& Kline, S. (2006). From satisfaction to delight: A model for the hotel industry. International Journal of Contemporary Hospitality Management, 18(4), 290-301.

Torres, E., \& Kline, S. (2013). From customer satisfaction to delight: Creating a new standard of service for the hotel industry. International Journal of Contemporary Hospitality Management, 25(5), 642-659.

Vinerean, S., Cetina, I., Dumitrescu, L., \& Tichindelean, M. (2013). The effects of social media marketing on online consumer behavior. International Journal of Business and Management, 8(4), 66-79. doi: 10.5539/ijbm.v8n14p66 
Journal of Youth Development | http://jyd.pitt.edu/ | Vol. 13 Issue 1-2 DOI 10.5195/jyd.2018.535

\section{Theming Camp}

Wassler, P., Li, X., \& Hung, K. (2015). Hotel theming in China: A qualitative study of practitioners' views. Journal of Travel \& Tourism Marketing, 32(6), 712-729.

Yohalem, N., Granger, R. C., \& Pittman, K. J. (2009). The quest for quality: Recent developments and future directions for the out-of-school-time field. New Directions For Youth Development, 129140.

Zetterberg, H. (1963). On theory and verification in sociology. Totowa, NJ: Bedminster Press. 
Journal of Youth Development | http://jyd.pitt.edu/ | Vol. 13 Issue 1-2 DOI 10.5195/jyd.2018.535 Theming Camp

\section{Appendix}

Example Template for a Narrative Guide to Theme Each Stage of a Structured Experience

\begin{tabular}{|l|l|}
\hline Title & \\
\hline Setting & \\
\hline Time & \\
\hline Plot/storyline & \\
\hline Characters & \\
\hline Props \\
\hline Act 1: Arrival \\
\hline Act 2: Decompression \\
\hline Act 3: Reception \\
\hline Act 4: Orientation \\
\hline
\end{tabular}

